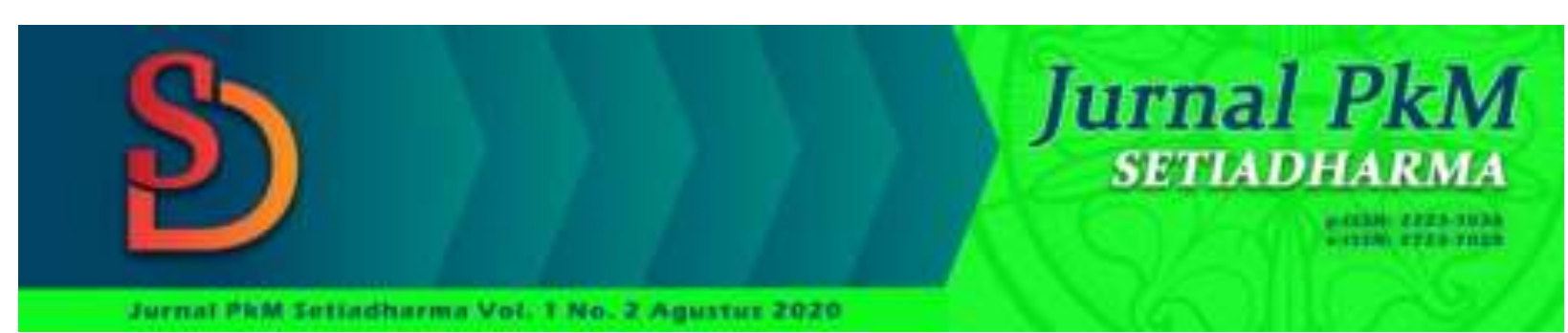

\title{
STRATEGI GEMBALA DALAM PEMANFAATAN AKTIVITAS JEMAAT MENUJU PERTUMBUHAN ROHANI
}

\author{
Andarias Tandi Barana ${ }^{1}$,Wahyu Sinta Delfia, ${ }^{2}$ Elisabet, ${ }^{3}$ \\ Sekolah Tinggi Teologi Injili Arastamar (SETIA) Jakarta \\ andretandibarana@gmail.com \\ elisabet.tarigas@gmail.com \\ wahyusinta@gmail.com
}

\begin{abstract}
Abstrak
Diterima:

01-09-2020

Direvisi:

16-09-2020

Diterbitkan:

30-09-2020

Kata Kunci:

Strategi,

Gembala,

Aktivitas Jemaat,

Pertumbuhan

Rohani

Keywords:

Tujuan dari penelitian ini adalah menemukan faktor-faktor penyebab serta masalah jemaat GKSI Filadelfia Buntu Barana kurang mengalami pertumbuhan rohani. Kemudian diarahkan melalui strategi gembala atau hamba Tuhan untuk meningkatkan pembinaan terhadap jemaat di tengah-tengah banyak kesibukan mereka yang mengutamakan pekerjaan dari pada ibadah atau bersekutu di gereja pada hari minggu. Metode yang di gunakan dalam penelitian ini adalah adalah: Pertama, metode penelitian perpustakaan yaitu penelitian terhadap buku-buku dan literatur yang berhubungan dengan penelitian ini sebagai acuan teoritis. Kedua, metode penelitian lapangan yaitu penelitian yang dilaksanakan secara langsung kepada objek penelitian dengan cara observasi atau pengamatan langsung di lapangan, dan wawancara. Kesimpulan penelitian ini adalah: pertama, terhamabtnya pertumbuhan rohani karena jemaat GKSI Buntu Barana karena belum adanaya pertobatan yang sesungguhnya bagi sebagian jemaat, Kedua, adanya kendala-kendala yang menghambat pertumbuhan rohani jemaat GKSI Buntu Barana, diantaranya adalah kurangnya persekutuan dan lingkungan sosial yang tidak mendukung pertumbuhan rohani jemaat. Ketiga, beberapa strategi yang efektif dalam meningkatkan kualitas rohani jemaat adalah dengan melakuakan perkunjugan di dalam kesibukan mereka dengan cara ikut terlibat dalam pekerjaan mereka yang menjadi kesibukannya, di luar jam ibadah selayaknya orang Kristen seperti: Ibadah Hari Minggu, Ibadah Kumpulan Rumah Tangga, Ibadah Sekolah Minggu, Ibadah Pemuda, kebaktian doa jemaat, dan melakukan perkunjugan jikalau mereka ada di rumah. Selain itu kami selaku hamba Tuhan sering membekali pemuda dengan berbagai kreativitas.
\end{abstract}

Strategy,

Shepherd,

Church Activity,

Spiritual Growth

\section{Abstract}

The purpose of this study is to find the causative factors and problems of the GKSI Filadelfia Buntu Barana congregation that are less experiencing spiritual growth. Than directed through the strategy of pastors or servants of God to increase formation of the congregation in the midst of many of their busy actifities that prioritize work rather than worship or followship in church on Sundays. The methods used in this study are: First, the library research method is a study of books end literature relating to this research as a theorectical reference. Second, the method of field research is research conducted directly to the object of research by observation or direct observation in the field, and interviews. The conclusions of this study are: first, the spiritual growth hampered by the GKSI Buntu Barana congregation because there is not yet real repentance for some congregations, second, there are obstacles that hinder the spiritual growth of the GKSI Buntu Barana congregation, including the lack of community and social environment that does not support spiritual growth of the church. Third, some effective strategies in increasing

\footnotetext{
${ }^{1}$ Mahasiswa Program Master Teologi Sekolah Tinggi Teologi Injili Arastamar Jakarta

${ }^{2}$ Mahasiswa Prodi PAK Sekolah Tinggi Teologi Injili Arastamar Jakarta

${ }^{3}$ Mahasiswa Prodi PAK Sekolah Tinggi Teologi Injili Arastamar Jakarta
} 
the spiritual quality of congregants are by engaging in their busy activities by getting involved in their busy work, outside of worship hours as Christians should: Suday Services, Hausehold Services, School Services Sunday, Youth Services, Church prayer Services, and visits if they are at home. In addition we as servents of Gad often provide young people with a variety of creativity.

\section{PENDAHULUAN}

\section{Latar Belakang Masalah}

Tidak dapat disangkal bahwa dalam sebuah gereja gembala adalah harapan dan tumpuan semua unsur yang ada dalam jemaat. oleh sebab itu kehadiran seorang gembala membawa pengaruh besar bagi semua anggota jemaat. . J.L. Ch Abineno mengatakan, "gembala adalah kunci keberhasilan sebuah jemaat. Gembala menjadi pengatur berjalannya setiap unsur-unsur dalam jemaat.4

Seorang gembala atau siapapun yang bertanggung jawab sebagai hamba Tuhan memiliki peran yang sangat penting dalam mengembangkan jemaat yang dihadapinya. Gembala yang bertanggung jawab harus memiliki tujuan yang jelas. Dengan adanya tujuan akan membuat gembala tersebut mampu melihat apa yang harus dihadapi dan dikerjakan dalam pelayanannya. John E. Ingouf mengatakan: "lebih banyak pemipin gereja gagal karena tidak mempunyai tujuan daripada yang gagal karena tidak berbakat." 5 Pernyataan tersebut mengindikasikan bahwa gembala yang sekalipun secara kemampuan terbatas tetapi semngat dan tujuan yang tinggi ada dalam dirinya lebih baik daripada gembala yang memiliki bakat dan kemampuan yang banyak tetapi tidak memiliki tujuan yang jelas.

Salah satu peran gembala yang perlu diperhatikan adalah bagaimana gembala memberikan tanggung jawab kepada rekan kerja dalam pelayanan ? J. Oswald Sanders mengatakan: "Satu definisi kepemimpinan ialah kemampuan untuk menyadari kemampuan-kemampuan dan kekurangan-kekurangan orang lain, digabungkan dengan kepandaian untuk memberikan tugas yang cocok bagi mereka masing-masing, sehingga mereka dapat melakukan tugas itu sebaik-baiknya."6 Selanjutnya Nehemia Mimery mengatakan: "salah satu fungsi gembala dalam jemaat yang tidak kala pentingnya adalah untuk melengkapi jemaat sehingga mereka menjadi aktif dan produktif, akhirnya mereka turut berpartisipasi membangun tubuh Kristus (Efesus 4: 12)." 7 Jadi seorang gembala harus mampu membagi tugas kepemimpinan kepada semua rekan kerja yang telah dibentuk.

Melihat pernyataan di atas, penulis melihat di GKSI Buntu Barana bahwa gembala sidang dan rekan kerja dalam pelayanan sudah melaksanakan tugas tersebut di atas dengan semaksimal mungkin. Pengkaderan dan pembagian tugas kepada setiap rekan kerja sudah dilaksanakan dengan maksimal. Ada beberapa jemaat pemantau pelayanan di GKSI jemaat Buntu Barana mengatakan: "pelayanan penggembalaan sudah berjalan dengan baik, jemaat sudah merasa puas dengan pelayanan yang sementara dijalankan

\footnotetext{
${ }^{4}$ J.L. Ch Abineno, Pedoman Praktis untuk Pelayanan Pastoral (Jakarta: BPK Gunung Mulia, 1999), hlm. 9

5 John E. Ingouf, Sekelumit tentang Gembala Sidang, (Bandung: Lembaga Literatur Baptis, 1988), hlm.14

${ }^{6}$ J. Oswald Sanders, Kepemimpinan Rohani, (Bandung: Yayasan Kalam Hidup, 2001), hlm. 138.

${ }^{7}$ Nehemia Mimery, Rahasia Tentang Penggembalaan jemaat (Mimery Press, t.t.), hlm. 6
} 
oleh gembala sekarang ini." ${ }^{8}$ Bahkan setiap tahun ada hamba Tuhan dari berbagai STT Arastamar yang di utus sebagai mahasiswa praktik yang turut mebantu dalam pelayanan. Dengan demikian dapat disimpulkan bahwa gembala dan rekan hamba Tuhan dalam pelayanannya di GKSI Jemaat Buntu Barana sudah melaksanakan tugasnya dengan baik.

Namun kenyatannya penulis yang meneliti melihat di GKSI Buntu Barana bahwa jemaat belum meresponi dengan baik belum melaksanakan persekutuan ibadah sebagai orang Kristen yang sudah bertobat. Lebih mengutamakan kesibukan pribadi dari pada persekutuan ibadah. Hamba Tuhan yang ada sudah mengarahkan sesuai dengan tanggung jawab masing-masing sebagai orang Kristen namun kenyataanya kurang terlibat dalam persekutuan secara maksimal.

Bertitik tolak dari latar belakang di atas, maka penulis terdorong untuk meneliti dengan judul "Strategi Gembala Jemaat dalam Pemanfaatan kesibukan Jemaat menjadi Ladang Pembinaan Rohani".

\section{Metode Penelitian}

Adapun metode penelitian yang digunakan peneliti dalam penyusunan penelitian ini yaitu metode deskriptif. Menurut Kamus kata "Deskriptif berasal dari kata deskripsi yang berarti pemaparan atau penggambaran dengan kata-kata secara jelas dan terinci, menggambarkan apa adanya." ${ }^{9}$ Moh. Nazir mengatakan:

"Metode deskriptif; metode dalam meneliti status kelompok manusia, suatu objek, suatu kondisi, suatu sistem pemikiran ataupun suatu peristiwa pada masa sekarang, adapun tujuan penelitian ini adalah untuk membuat deskripsi, gambaran atau lukisan secara sistematis, faktual dan akurat mengenai faktafakta, sifat-sifat serta hubungan antara fenomena yang diselidiki."10

Dengan demikian jenis penelitian yang penulis gunakan dalam karya ilmiah ini adalah metode penelitian deskriptif yaitu mengadakan penelitian yang sifatnya menggambarkan atau memaparkan hasil penelitian dengan kata-kata yang jelas berdasarkan data kualitatif. Penulis menggambarkan mengenai peran gembala sidang melayani jemaat yang kurang aktif dalam persekutuan di GKSI Buntu Barana.

\section{Instrumen dan skala pengukuran}

Pada bagian ini, peneliti bertindak sebagai instrumen yaitu mencoba menentukan cara memperoleh data-data sehubungan kedua variabel tersebut. Penulis menggunakan metode interview atau wawancara, atau kuesioner lisan. Suharsimi Arikunto mengatakan, "Wawancara adalah sebuah dialog dilakukan oleh pewawancara untuk memperoleh informasi dari terwawancara." 11 Dalam melaksanakan metode tersebut, penulis menggunakan interview bebas terpimpin, yaitu pewawancara membawa pedoman yang merupakan garis besar dari data yang dibutuhkan.

\footnotetext{
${ }^{8}$ Matius Arruan, Marten T Pasoso', Wawancara oleh Penulis, Tana Toraja 01 juli 2020.

${ }^{9}$ Kamus Besar Bahasa Indonesia, s.v. "deskripsi”

${ }^{10}$ Moh. Nazir, Metode Penelitian (Jakarta: Ghalia Indonesia, 1988), hlm. 63

${ }^{11}$ Suharsimi Arikunto, Prosedur Penelitian (Jakarta: Rineka Cipta, 2002), hlm. 109
} 
STRATEGI GEMBALA DALAM PEMANFAATAN AKTIVITAS ... (Andarias Tandi Barana, Wahyu Sinta Delfia, \& Elisabet)

\section{Jenis Data}

Jenis data yang digunakan oleh penulis dalam karya ilmiah ini adalah data kualitatif dan kuantitatif dimana data yang ditemukan berupa data dalam bentuk pengamatan langsung dan informasi baik secara lisan maupun tertulis. Fo'arota Telambanua mengatakan: "Data kualitatif adalah data yang dinyatakan dalam bentuk bukan angka." 12 Data kualitatif yang didapatkan dalam penelitian ini yakni observasi dan wawancara. Selanjutnya Ugiyono mengatakan: "Data kuantitatif adalah data yang berbentuk angka atau data kualitatif yang diangkakan (skoring)."13 Data kuantitatif yang didapatkan dalam penelitian ini adalah data yang berupa angka seperti jumlah anggota, dan jumlah Penatua GKSI Buntu Barana.

\section{Sumber Data}

Adapun yang menjadi sumber data dalam penelitian ini adalah: Data Primer dan Data Sekunder. Menurut kamus "Data Primer adalah data yang diperoleh seorang peneliti langsung dari obyeknya" dan "Data Sekunder adalah data yang diperoleh seorang peneliti secara tak langsung dari obyeknya, tetapi melalui sumber lain baik lisan maupun tulisan."14

Dengan demikian, yang menjadi data Primer adalah para pengurus gereja, baik melalui observasi maupun wawancara kepada beberapa jemaat atas ketidak aktifannya dalam persekutuan, dan yang menjadi data Sekunder yaitu melalui informasi dan gambaran tentang peran gembala dalam hubungannya dengan pertumbuhan iman jemaat serta landasan teori dan penelitian buku yang berhubungan dengan pertumbuhan iman jemaat.

\section{Teknik Pengumpulan Data}

Teknik pengumpulan data yang digunakan dalam penelitian ini adalah observasi dan wawancara:

\section{a) Observasi}

Riduwan mengatakan, "Observasi adalah suatu cara mengumpulkan data secara langsung ke objek penelitian untuk melihat dari dekat kegiatan yang dilakukan." 15 Adapun observasi yang peneliti lakukan yaitu observasi secara langsung yaitu dengan meneliti dan mengoreksi aktivitas jemaat serta pekerjaan yang di lakukannya setiap hari.

\section{b) Wawancara}

Koentjaraningrat mengatakan, "Metode wawancara atau metode interview, mencakup cara yang dipergunakan seseorang, untuk tujuan suatu tugas tertentu, mencoba mendapatkan keterangan atau pendirian secara lisan dari seorang responden,

\footnotetext{
${ }^{12}$ Fo'arota Telaumbanua, Pengelolaan Data Penelitian Perbandingan dan Perhubungan (Jakarta: FKIP Universitas Kristen Indonesia, 2006), hlm. 10

${ }^{13}$ Ugiyono, Statistika untuk Penelitian (Bandung: ALFABETA, 2005), hlm. 15

${ }^{14}$ Salim dan Yenny Salim, Kamus Besar Indonesia Kontemporer ( Jakarta: Modern English Press, 1995),s.v. "Data Primer dan Data Sekunder."

15 Riduwan, Belajar Muda Penelitian untuk Guru-Karyawan dan Peneliti Pemula (Bandung: Alfabeta, 2005), hlm. 62
} 
dengan bercakap-cakap berhadapan muka dengan orang itu."16 Lanjut Sugiyono mengatakan, "Wawancara (interview) atau yang juga disebut kuesioner adalah merupakan suatu cara untuk memperoleh informasi langsung dari sumbernya." 17 Dalam penelitian ini, peneliti melakukan wawancara untuk mendapatkan data yang valid dan dapat dipertanggungjawabkan. Adapun jenis wawancara yang digunakan yaitu wawancara terpimpin dan wawancara bebas terpimpin, sesuai dengan permasalahan yang sedang diteliti. Dengan demikian peneliti melakukan wawancara kepada beberapa jemaat

\section{Pelaksanaan}

\section{Strategi hamba Tuhan}

Dengan Melihat potensi yang ada di keseluruhan masyarakat bahwa di dalam kehidupan masyarakat perdesaan sering kita jumpai kebersamaan dalam bergotong royong untuk mengangkat suatu pekerjaan. Ini pun yang kami jumpai pada jemaat Filadelfia Buntu Barana mereka lebih memancarkan kekeluargaan, kerukunan, keperdulian antara satu sama lain, baik dari segi kehidupan keluarga maupun sosial. Salah satu contoh kebersamaan yang dilakukan adalah pada saat pembangunan gedung gereja dimana semua anggota jemaat ikut terlibat. laki-laki mengerjakan pembangunan gedung gereja, sedangkan perempuan membantu dalam mempersiapkan makanan dan minuman.

Kebersamaan jemaat tidak hanya dalam pembangunan gedung gereja saja, tetapi dalam hal bekerja sebangai petani/pekebun jemaat tetap bekerja sama. Bekerja sama yang dimaksud dalam hal ini adalah kaum wanita membuat kelompok serta jadwal bekerja (bergiliran) untuk menggarap lahan dari setiap anggota kelompok.

Berkebun merupakan sebagian besar mata pencarian jemaat Filadelfia Buntu Barana. Jemaat menanam berbagai jenis tanaman seperti Kol, Sawi Putih, Bawang, Tomat, Cabe, Kopi, Cengkeh, Coklat, Jagung, dll. Sebagian dari jenis sayuran ini memerlukan perawatan yang menyita waktu dari jemaat sehingga jemaat lebih banyak memakai waktu mereka untuk di kebun dan jarang berada di rumah. Bagi kaun wanita yang semestinya mengurus rumah tangga dan anak justru memilih untuk menghabiskan waktu mereka di kebun oleh karena tuntutan ekonomi keluarga. Berkebun merupakan prioritas bagi jemaat sehingga mereka melalaikan prioritas yang sesungguhnya (mencari Tuhan).

Jika dilihat dari segi kehidupan sosial jemaat GKSI Filadelfia Buntu Barana memiliki rasa kebersamaan dan kepedulian yang tinggi, namun dalam hal kerohanian mereka kurang. Oleh karena itu pentingnya peran hamba Tuhan menentukan strategi di tengah-tengah jemaat sebagai agen perubahan (meningkatnya kualitas iman) bagi jemaat dengan cara ikut serta dalam kegiatan keseharian jemaat (petani/pekebun). Keterlibatan hamba Tuhan dalam keseharian jemaat bisa membantu pertumbuhan rohani jemaat. Karena didalamnya hamba Tuhan memberi pemahaman tentang Firman Tuhan.

\footnotetext{
${ }^{16}$ Koentjaraningrat, Metode-metode penelitian masyarakat (Jakarta: PT.Gramedia, 1981), hlm. 162

${ }^{17}$ Sugiyono, memahami Penelitian Kualitatif (Bandung: Alfbeta, 2005), hlm. 62
} 
STRATEGI GEMBALA DALAM PEMANFAATAN AKTIVITAS ... (Andarias Tandi Barana, Wahyu Sinta Delfia, \& Elisabet)

\section{Wadah Pemberitaan Injil}

Manusia hanya sering memperhatikan kebutuhan yang kelihatan seperti sandang, pangan, papan dan pekerjaan. Namun Allah memandang kebutuhan manusia yang tidak kelihatan secara jasmani itu jauh lebih penting yaitu keselamatan (kehidupan kekal) bukan berarti Allah tidak perduli dengan kebutuhan jasmani, Allah juga sangat perduli akan kebutuhan ini.

Menurut Adolf Harnack dari The mision an expansion of the christianity berkata, kita harus menyadari bahwa misi terbesar dari kekeristen dalam kenyataannya diselesaikan melalui para penginjil yang menginjil secara informal (tidak resmi) ${ }^{18}$. Demikian pula dengan wadah penginjilan tiak harus dilaksanakan didalam gereja karena inti dari pekabaran injil bukan tentang dimana kita menginjili tetapi kepada siapa kita memberitakan injil.

Jika kita lihat dari segi kehidupan jemaat Filadelfia Buntu Barana yang kehidupan sehari-harinya sibuk bekerja di kebun dan jarang dijumpai saat hamba Tuhan melakukan perkunjungan, tentu hal ini akan menghambat hamba Tuhan dalam melaksanakan penginjilan. Oleh karena itu penting bagi seorang hamba Tuhan memiliki strategi agar injil Kristus tetap diberitakan.

Ada beberapa strategi yang bisa dilakukan hamba Tuhan kepada jemaat Filadelfia Buntu Barana

\section{a) Bersosialisasi dengan baik}

Bersosialisasi atau menjalin hubungan yang baik dengan lingkungan sekitar juga dapat menghindari kecurigaan atau prasangka yang buruk tentang diri kita sebagai hamba Tuhan yang dimana sebenarnya kita adalah seorang pendatang yang di berikan tugas untuk menjalankan amanat agung Yesus Kristus (Matius 28:19-20) di tengahtengah jemaat Filaelfia Buntu Barana itulah pentingnya kita bersosialisasi dengan baik kepada jemaat/lingkungan sekitar.

\section{b) Menjangkau melalui pekerjaan (berkebun)}

Seperti yang kita tahu bahwa sebagian besar pekerjaan jemaat adalah petani/berkebun maka dari itu kita sebagai hamba Tuhan harus bisa menyempatkan diri untuk terjun langsung dalam ladang pekerjaan yang dikerjakan jemaat. Tentu dalam berlangsungnya pekerjaan tersebut tidak terlepas dari penginjilan kepada jemaat, dengan memanfaatkan kesempatan ini disela-sela kesibukan jemaat pada saat bekerja memiliki kelebihan dibandingkan penginjilan secara konvensional. Kelebihannya antara lain ada pada hubungan yang lebih personal(lebih dapat memunculkan keterbukaan jemaat). Sehingga kita sebagai hamba Tuhan bisa mengetahui penyebab apa yang membuat jemaat tidak bisa menyempatkan diri untuk beribadah, serta memberikan nasehat atau bimbingan kepada jemaat untuk memprioritaskan Tuhan.

\section{c) Perkunjungan di Rumah}

Peluang hamba Tuhan untuk bisa bertemu langsung di rumah jemaat memang sangat sedikit, akan tetapi kami sebagai hamba Tuhan harus mengupayakan agar

\footnotetext{
${ }^{18}$ Petrus Kwik, S.Th. Dkk, Renungan Haria Spirit, (Solo: Spirit Graphic, 2007), hlm. 1
} 
perkunjungan ke rumah-rumah tetap berjalan. Karena menurut pandangan kami jemaat yang sering dikunjungi hamba Tuhan akan merasa lebih senang, mereka merasa bahwa ada yang mempedulikan masalah keluarga maupun hidup mereka.

Namun sangat disayangkan, pekerjaan yang menuntut jemaat untuk memenuhi kebutuhan hidup hingga jemaat melalaikan kebutuhan paling utama, terutama bersekutu dengan Tuhan. Oleh karena itu sangat penting bagi hamba Tuhan memiliki komunikasi yang baik dengan jemaat, sehingga dapat diketahui kapan jemaat ada di rumah dan dapat melakukan perkunjungan dan penginjilan kepada jemaat.

Dari kesibukan jemaat itu kami mengharapkan tekun dalam persekutuan. Abraham Kuyper mengatakan: "setiap persekutuan dari jiwa menuntut kehadiran secara fisik, karena kita adalah satu mahkluk yang utuh. ${ }^{19}$ Mazmur 73: 23 berkata: Tetapi aku tetap di dekat-Mu yang berarti bahwa Asaf ingin selalu berjalan dengan Allah. dan Allah mengiginkan setiap umat-Nya dekat kepada-Nya seperti di dalam persekutuan.

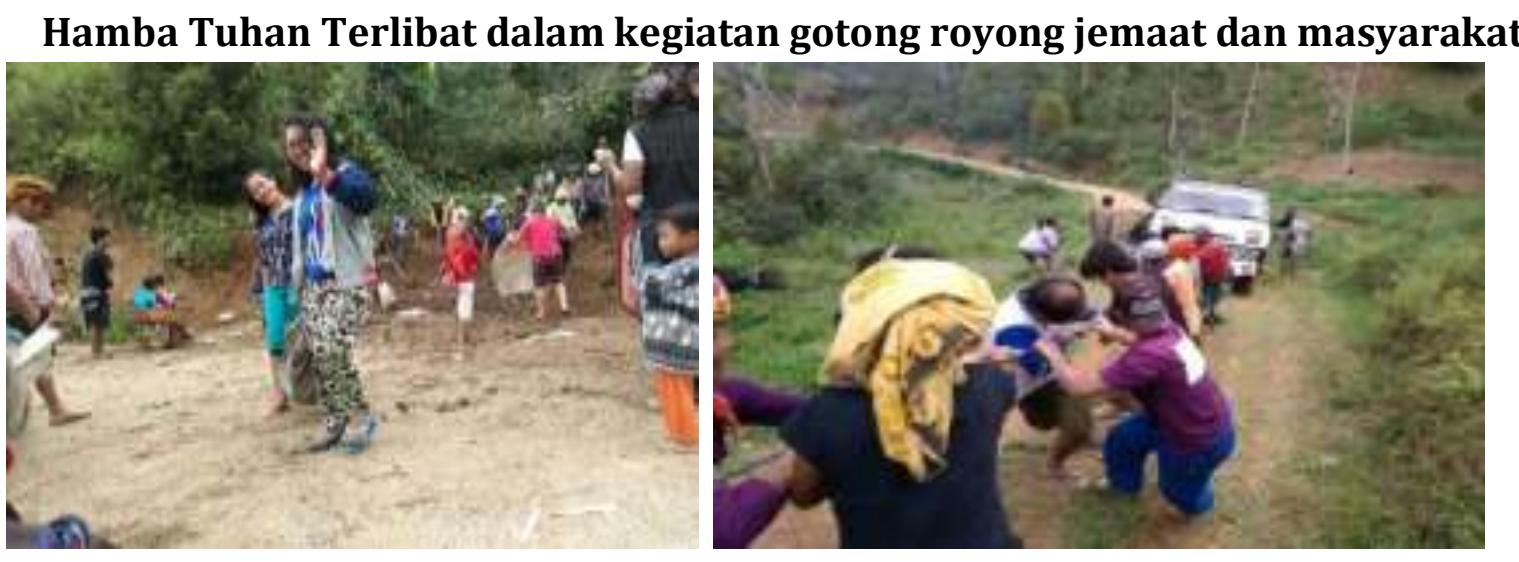

Ikut bekerja bersama jemaat
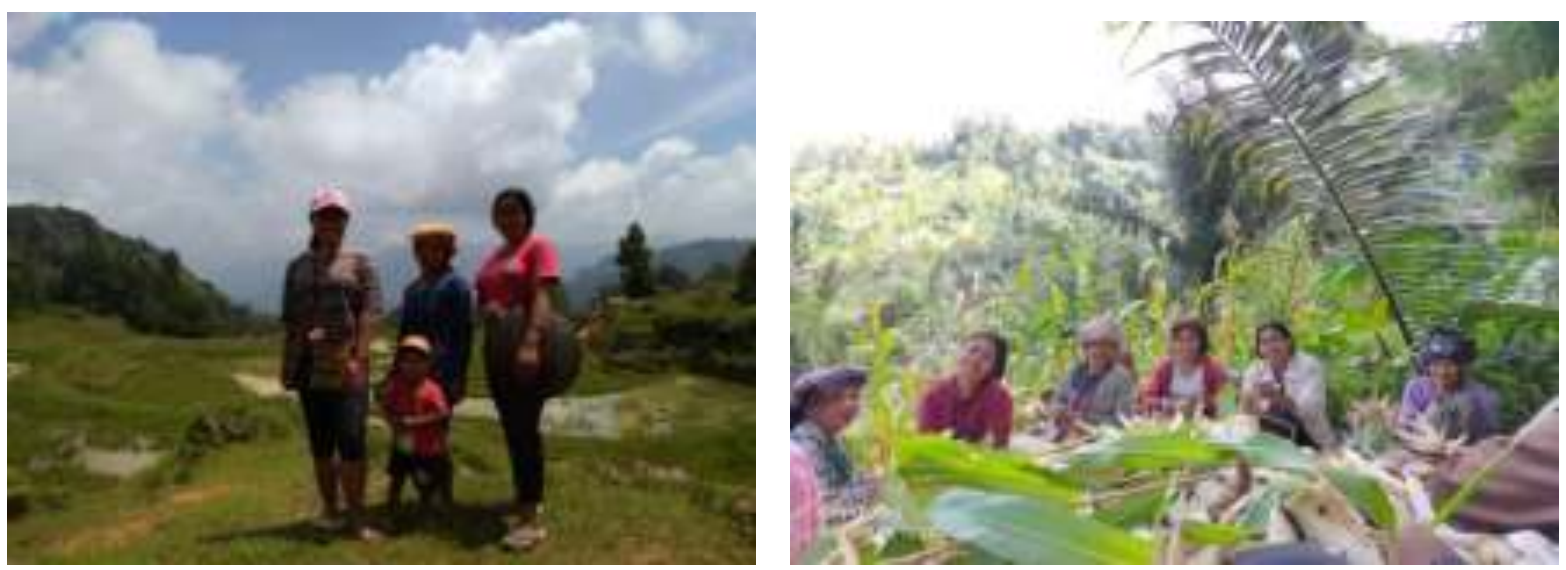

${ }^{19}$ Abraham Kuyper, Mendekat kepada Allah, (Surabaya: Momentum,2013), hlm. 132 

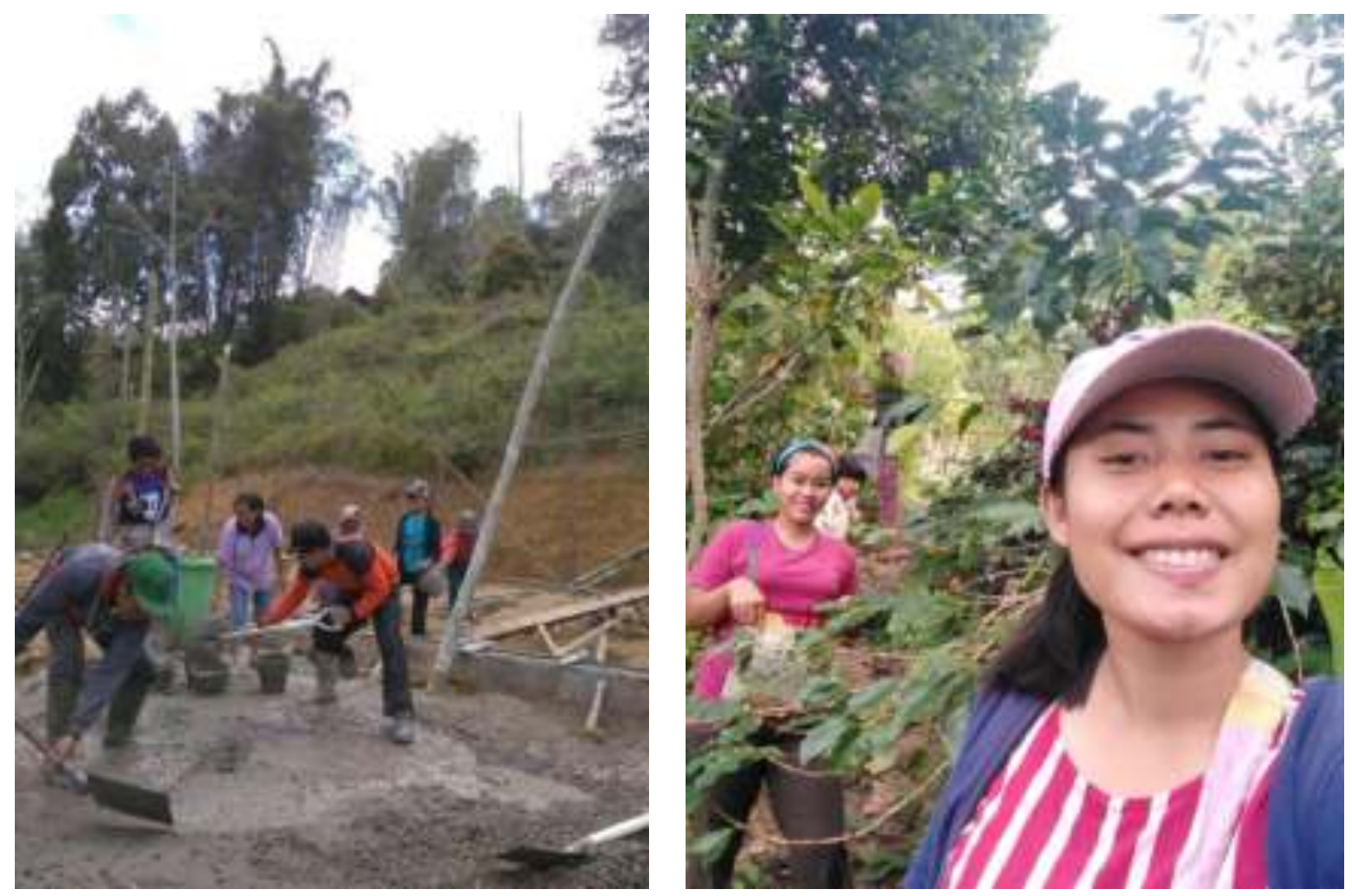

\section{Kesimpulan}

Demikianlah strategi yang dapat di kerjakan oleh kami selaku hamba Tuhan yang menjadi pemimpin bagi jemaat. Sebagaimana Kristus menjadi teladan bagi para murid, bahkan semua hamba Tuhan yang di berikan tugas Agung dari Tuhan mengemban tugas sebagai gembala Jemaat. demikian pun yang dapat kami terapkan di dalam pelayanan bagi mereka yang kurang aktif di dalam persekutuan ibadah jemaat dengan penjangkauan seperti: Pertama, mengembangkan bentuk-bentuk pelayanan yang dapat menjawab pergumulan jemaat di tengah kesibukan mereka. Kedua, gerja mendukung kelompok yang di buat pemerintah sebagai lapangan kerja baru yang di dalamnya dapat bekerja sama. Ketiga, ketelibatan hamba Tuhan dalam kegiatan masyarakat sekitar gereja akan merasakan dampak dari pelayanan sehingga mereka yang belum percaya Yesus ada kemauan ikut beribadah menjadi jemaat tetap. Keempat, mempergunakan tenaga pemuda pemudi dalam berkreatifitas dengan maksud menjadi modal mereka di masa depan degan kreativitas itu. 


\section{Kepustakaan}

Abineno, J.L. Ch, Pedoman Praktis untuk Pelayanan Pastoral. Jakarta: BPK Gunung Mulia, 1999

Arikunto, Suharsimi, Prosedur Penelitian. Jakarta: Rineka Cipta, 2002

Ingouf, John E. Sekelumit tentang Gembala Sidang. Bandung: Lembaga Literatur Baptis, 1988

Kamus besar Bahasa Indonesia. Jakarta: Balai Pustaka, 1987

Koentjaraningrat, Metode-metode penelitian masyarakat. Jakarta: PT.Gramedia, 1981

Kuyper, Abraham, Mendekat kepada Allah. Surabaya: Momentum,2013

Kwik, Petrus, S.Th. Dkk, Renungan Haria Spirit, Solo: Spirit Graphic, 2007

Mimery, Nehemia, Rahasia Tentang Penggembalaan jemaat. Mimery Press, t.t.

Nasir, Moh, Metode Penelitian. Jakarta: Ghalia Indonesia, 1988

Riduwan, Belajar Muda Penelitian untuk Guru-Karyawan dan Peneliti Pemula. Bandung: Alfabeta, 2005

Salim dan Yenny Salim, Kamus Besar Indonesia Kontemporer. Jakarta: Modern English Press, 1995

Sanders, J. Oswal, Kepemimpinan Rohani, Bandung: Yayasan Kalam Hidup, 2001

Sugiyono, memahami Penelitian Kualitatif. Bandung: Alfbeta, 2005

Telumbanua, Fo'arota, Pengelolaan Data Penelitian Perbandingan dan Perhubungan Jakarta: FKIP Universitas Kristen Indonesia, 2006

Ugiyono, Statistika untuk Penelitian. Bandung: ALFABETA, 2005 